\title{
Intramolecularly-stabilized Group 14 Alkoxides - Promising Precursors for the Synthesis of Group 14-Chalcogenides by Hot- Injection Method
}

\author{
Monika Rusek, Georg Bendt, Christoph Wölper, Dieter Bläser and Stephan Schulz*
}

Dedicated to Prof. G. Schmid on the occasion of his 80th birthday.

\begin{abstract}
Intramolecularly-stabilized germanium, tin and lead alkoxides of the type $\mathrm{M}\left(\mathrm{OCH}_{2} \mathrm{CH}_{2} \mathrm{NR}_{2}\right)_{2}(\mathrm{R}=\mathrm{Et}, \mathrm{M}=\mathrm{Ge} 1 ; \mathrm{R}=\mathrm{Me}$, $\mathrm{M}=\mathrm{Sn} 2, \mathrm{~Pb} 3$ ) are suitable precursors for the synthesis of group 14 chalcogenides $\mathrm{ME}(\mathrm{M}=\mathrm{Ge}, \mathrm{Sn}, \mathrm{Pb} ; \mathrm{E}=\mathrm{S}, \mathrm{Se}, \mathrm{Te})$ in scrambling reactions with $\left(\mathrm{Me}_{3} \mathrm{Si}\right)_{2} \mathrm{~S}$ and $\left(\mathrm{Et}_{3} \mathrm{Si}\right)_{2} \mathrm{E}(\mathrm{E}=\mathrm{Se}, \mathrm{Te})$ at moderate temperatures via hot injection method. The reactions proceed with elimination of the corresponding silylether as was proven by in situ ${ }^{1} \mathrm{H}$ NMR spectroscopy. The solid state structures of the homoleptic complex 1 and the heteroleptic complex $\mathrm{CIGe}\left(\mathrm{OC}_{2} \mathrm{H}_{4} \mathrm{NEt}_{2}\right) \mathbf{4}$ were determined by single crystal X-ray diffraction, while the group 14 chalcogenides were characterized by XRD, SEM and EDX.
\end{abstract}

\section{Introduction}

Group 14 chalcogenides are considered as highly promising materials for technical application in thermoelectric generators, optoelectronic devices, temperature sensors, telecommunication, holographic recording systems and in memory relays. ${ }^{[1]}$ Thermoelectric (TE) materials have received growing interest during the last years since they allow the conversion of waste heat into renewable energy (Seebeck effect), while the opposite Peltier effect is used for cooling devices. Technical devices without any moving components were shown to run without maintenance for at least 30 years. The efficiency of thermoelectric materials is defined by the dimensionless figure of merit

$$
Z T=\frac{S^{2} \sigma T}{\kappa},
$$

in which S stands for the Seebeck coefficient, $\sigma$ for the electric, $k$ for the thermal conductivity und $T$ for the absolute temperature. Effective thermoelectric materials require therefore good electrical transport properties and high Seebeck coefficients, while their thermal conductivity should be as low as possible. The higher the $\mathrm{ZT}$ value, the higher is the TE conversion efficiency and a ZT value of at least 1 is necessary. ${ }^{[1,2]}$

Tetradymite-type binary and multinary group $\mathrm{V}-\mathrm{VI}$ (heterostructured) materials such as $\mathrm{Bi}_{2} \mathrm{Te}_{3},\left(\mathrm{Sb}_{\mathrm{x}} \mathrm{Bi}_{1-\mathrm{x}}\right)_{2} \mathrm{Te}_{3}$ or $\left(\mathrm{Sb}_{\mathrm{x}} \mathrm{Bi}_{1-\mathrm{x}}\right)_{2}\left(\mathrm{Se}_{\mathrm{y}} \mathrm{Te}_{1-\mathrm{y}}\right)_{3},{ }^{\left[{ }^{3]}\right.}$ whose excellent thermoelectric properties are known for decades, and IV-VI semiconductors belong to the

[a] S. Schulz, ${ }^{*}$ M. Rusek, G. Bendt, D. Bläser, C. Wölper Faculty of Chemistry, Inorganic Chemistry, and Center for Nanointegration Duisburg-Essen (CENIDE), University of DuisburgEssen, Universitätsstr. 7, 45114 Essen, Germany

E-mail: stephan.schulz@uni-due.de

Supporting information for this article is given via a link at the end of the document. most promising thermoelectric materials and have been studied in detail. ${ }^{[4]}$ For instance, the thermoelectric generator MMRTG used by the NASA is based on the n-type PbTe and the p-type $\mathrm{PbSnTe}$ (PST) as well as $(\mathrm{GeTe})_{\times}\left(\mathrm{AgSbTe}_{2}\right)_{1-\mathrm{x}}$ (TAGS). ${ }^{[2]}$ The development of nanostructured $2 \mathrm{D}$ quantum well structures as well as nanostructured multiphase systems in the last decade has resulted in substantially improved $\mathrm{ZT}$ values ${ }^{[5]}$ and record values of up to 2.0 were reported for $\mathrm{PbTe}$, which is a classical and best TE material used at mid-temperatures. ${ }^{[6]}$ However, the toxicity of $\mathrm{Pb}$ and the high cost for Te prompted the interest to alternative materials with nontoxic and abundant elements. $\mathrm{SnSe}$ is a narrow band-gap semiconductor with an indirect band gap of $0.90 \mathrm{eV}$ at $25^{\circ} \mathrm{C}$ and a direct band gap of $1.30 \mathrm{eV}$ at high temperature, which finds technical applications in photovoltaic devices such as solar cells since its band gap falls within the optimum band gap. ${ }^{[4,7]}$ Very recent studies also demonstrated that $\mathrm{SnSe}$ also shows very promising thermoelectric properties ${ }^{[8]}$ and an outstanding $\mathrm{ZT}$ value of 2.6 at $923 \mathrm{~K}$ was reported by Kanatzidis et al. for p-type SnSe single crystals along one of the crystallographic directions. ${ }^{[9]}$ This very high $\mathrm{ZT}$ values was explained as a result from the extremely low thermal conductivity. Germanium chalcogenides such as germanium sulfide (GeS) and selenide (GeSe), which are suitable materials in photovoltics, batteries and photodetectors, are also currently investigated as alternative materials for cadmium and lead chalcogenides. Again, the replacement of toxic cadmium and lead in the corresponding chalcogenides is one of the driving forces. Both p-type chalcogenides have a orthorhombic crystal structures and bandgaps between $1.55-1.65 \mathrm{eV}(\mathrm{GeS})$ and 1.1$1.2 \mathrm{eV}(\mathrm{GeSe})$.

We are generally interested in the development of new (metal organic) precursors for the solution-based synthesis of group 14 chalcogenide nanoparticles as well as the deposition of thin films by gas-phase based processes such as chemical vapor deposition (CVD) or atomic layer deposition (ALD). Recently, we reported on the synthesis of highly stoichiometric, crystalline $\mathrm{GeTe}$ nanoparticles by reaction of $\mathrm{GeCl}_{2}$ (dioxane) with $\mathrm{Te}\left(\mathrm{SiEt}_{3}\right)_{2} \cdot{ }^{[11]}$ Unfortunately, the low vapor pressure of $\mathrm{GeCl}_{2}$ (dioxane) hampers its use as precursor in gas-phase based processes, which is also true for crystalline single source precursors such as $\left[\left(\mathrm{Me}_{3} \mathrm{Si}\right)_{2} \mathrm{~N}\right]_{2} \mathrm{Ge}(\mathrm{ER})_{2} \quad(\mathrm{E}=\mathrm{S}$, Se, Te $)$, $\mathrm{Me}_{2} \mathrm{Si}(\mathrm{Nt}-\mathrm{Bu})_{2} \mathrm{Ge}(\mathrm{ER})_{2}(\mathrm{E}=\mathrm{S}, \mathrm{Se})$ and $\left[\left(\mathrm{Me}_{3} \mathrm{Si}\right)_{2} \mathrm{~N}\right]_{2} \mathrm{Sn}(\mathrm{ER})_{2}(\mathrm{E}=$ $\mathrm{S}$, Se, Te), ${ }^{[12]}$ which have been recently applied in the wet chemical synthesis of group 14 chalcogenides. ${ }^{[13]}$ Our interest in volatile, ideally liquid precursors therefore prompted us to investigate group 14 aminoalkoxides, which may form intermolecularly base-stabilized monomeric compounds. Comparable ligands were recently successfully used for the stabilization of monomeric antimony and bismuth complexes 
$\mathrm{M}\left(\mathrm{OC}_{2} \mathrm{H}_{4} \mathrm{NMe}_{2}\right)_{3}(\mathrm{M}=\mathrm{Sb}, \mathrm{Bi})$, which are suitable precursors for the synthesis of $\mathrm{Sb}_{2} \mathrm{E}_{3}$ and $\mathrm{Bi}_{2} \mathrm{E}_{3}$ nanoparticles in reactions with bis(trialkylsilyl)chalcogenides $\mathrm{E}\left(\mathrm{SiR}_{3}\right)_{2}\left(\mathrm{E}=\mathrm{S}\right.$, Se, Te). ${ }^{[14]}$

We herein report on the synthesis of three intramolecularlystabilized homoleptic germanium, tin and lead alkoxides of the general form $\mathrm{M}\left(\mathrm{OCH}_{2} \mathrm{CH}_{2} \mathrm{NR}_{2}\right)_{2}(\mathrm{R}=\mathrm{Et}, \mathrm{M}=\mathrm{Ge} 1 ; \mathrm{R}=\mathrm{Me}, \mathrm{M}=$ $\mathrm{Sn} \mathrm{2,} \mathrm{Pb} 3)$ and $\mathrm{ClGe}\left(\mathrm{OC}_{2} \mathrm{H}_{4} \mathrm{NEt}_{2}\right) \quad 4$ and the solid state structures of $\mathbf{1}$ and $\mathbf{4}$. In addition, the promising potential of $\mathbf{1}-\mathbf{3}$ to serve as soluble precursors for the synthesis of group 14 chalcogenides $M E(M=G e, S n, P b ; E=S, S e, T e)$ in reactions with $\left(\mathrm{R}_{3} \mathrm{Si}\right)_{2} \mathrm{E}(\mathrm{E}=\mathrm{S}$, Se, Te; $\mathrm{R}=\mathrm{Me}$, Et $)$ at moderate temperatures via hot injection method is demonstrated.

\section{Results and Discussion}

The homoleptic bisalkoxides $\mathrm{M}\left(\mathrm{OCH}_{2} \mathrm{CH}_{2} \mathrm{NR}_{2}\right)_{2}(\mathrm{R}=\mathrm{Et}, \mathrm{M}=\mathrm{Ge}$ 1; $\mathrm{R}=\mathrm{Me}, \mathrm{M}=\mathrm{Sn} 2, \mathrm{~Pb}$ 3) were synthesized according to a slightly modified literature route by reaction of $\mathrm{MCl}_{2}$ with two equivalents of freshly prepared $\mathrm{LiOCH}_{2} \mathrm{CH}_{2} \mathrm{NR}_{2} \cdot{ }^{[15]} 1$ was purified by vacuum distillation and single crystals of the heteroleptic complex $\left[\mathrm{Ge}(\mathrm{Cl}) \mathrm{OCH}_{2} \mathrm{CH}_{2} \mathrm{NR}_{2}\right]_{2} 4$ were isolated as side-product in very low yield $(4 \%)$ in the distillation flask. The formation of $\mathbf{4}$ most likely results from the presence of a slight excess of $\mathrm{GeCl}_{2}$ (dioxane), which then reacts with 1 with formation of 4 as was reported by for the Me-analogue $\mathrm{Ge}\left(\mathrm{OCH}_{2} \mathrm{CH}_{2} \mathrm{NMe}_{2}\right)_{2} \cdot{ }^{[16]}$

$$
\begin{gathered}
\mathrm{MCl}_{2}+2 \mathrm{LiOC}_{2} \mathrm{H}_{4} \mathrm{NR}_{2} \frac{\mathrm{Et}_{2} \mathrm{O}, 0^{\circ} \mathrm{C}}{-2 \mathrm{LiCl}} \mathrm{M}\left(\mathrm{OC}_{2} \mathrm{H}_{4} \mathrm{NR}_{2}\right)_{2} \\
\mathrm{R}=\mathrm{Et}, \mathrm{M}=\mathrm{Ge} \mathbf{1} ; \mathrm{R}=\mathrm{Me}, \mathrm{M}=\mathrm{Sn} \mathbf{2}, \mathrm{Pb} 3
\end{gathered}
$$

Scheme 1. Synthesis of $1-3$

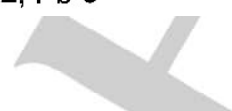

The ${ }^{1} \mathrm{H}$ and ${ }^{13} \mathrm{C}$ NMR chemical shifts of 2 and $\mathbf{3}$ agree well with values previously reported, ${ }^{[17]}$ and 1 also shows comparable values. The room temperature ${ }^{1} \mathrm{H}$ NMR spectra of 1 (Fig. S1) and 3 display sharp resonances whereas that of 2 shows two broad triplets for the $\mathrm{OCH}_{2} \mathrm{CH}_{2} \mathrm{~N}$ moiety and one singlet for the $\mathrm{NMe}_{2}$ group (Fig. S2). The broad signals point to rearrangement reactions in solution, during which the dative $\mathrm{Ge}-\mathrm{N}$ donor bonds open and close. Upon heating, the resonances in the ${ }^{1} \mathrm{H}$ NMR of 2 become slightly sharper.

Single crystals of $\mathbf{1}$ were obtained by in situ crystallization directly on the diffractometer using a miniature zone melting procedure with focused infrared-laser-radiation at $250 \mathrm{~K} \cdot{ }^{[18]}$ Figures 2 and 3 show the crystal structures of 1 and 4.1 crystallizes in the monoclinic space group $P 2_{1} / C$ with one formula unit in the asymmetric unit, while 4 belongs to the triclinic crystal system with space group $P-1$ and the molecule is placed on a center of inversion. The $\mathrm{Ge}$ atoms adopt a $2+2$ coordination mode in both compounds. The inner coordination sphere is formed by $\mathrm{O} 1$ and $\mathrm{O} 11$ (1) and $\mathrm{O} 1$ and $\mathrm{Cl} 1$ (4), respectively. Roughly perpendicular to the resulting planes, N1 and N11 (1) as well as $\mathrm{N} 1$ and $\mathrm{O} 1 \# 1$ (4) complete the coordination sphere.
The bond lengths (see captions of Figure 1 and 2) of the outer coordination sphere clearly exceed the sum of the covalent radii (Ge 1.21, N 0.71, O 0.63, Cl $0.99 \AA$ ) , ${ }^{[19]}$ but they are well below the sum of the van der Waals radii (Ge 2.11, N 1.55, O 1.52 A). ${ }^{[20]}$ Comparable findings were observed for analogous homoleptic $\left[\mathrm{M}\left(\mathrm{OCH}_{2} \mathrm{CH}_{2} \mathrm{NMe}_{2}\right)_{2} ; \mathrm{M}=\mathrm{Ge}, \mathrm{Sn}\right]^{[21]}$ and heteroleptic $\left[\mathrm{Ge}\left(\mathrm{N}_{3}\right) \mathrm{OC}_{2} \mathrm{H}_{4} \mathrm{NMe}_{2}\right]^{[22]}$ intramolecular-stabilized complexes containing a dimethylamino side-arm donor function. 1 shows almost identical $\mathrm{Ge}-\mathrm{O}$ bond lengths $[\mathrm{Ge}(1)-\mathrm{O}(1)$ 1.8593(11), $\mathrm{Ge}(1)-\mathrm{O}(11) 1.8608(11) \AA$ \} compared to $\mathrm{Ge}\left(\mathrm{OCH}_{2} \mathrm{CH}_{2} \mathrm{NMe}_{2}\right)_{2}$ [1.868(1), 1.864(1); 1.861(1), 1.870(1) A]. In contrast, the Ge-N bond lengths in 1 [Ge(1)-N(11) 2.3595(12), $\mathrm{Ge}(1)-\mathrm{N}(1)$ $2.4331(12) \AA]$ are slightly elongated compared to those of $\mathrm{Ge}\left(\mathrm{OCH}_{2} \mathrm{CH}_{2} \mathrm{NMe}_{2}\right)_{2}$ [2.329(2), 2.337(2); 2.324(2), 2.346(2) $\AA$ ], respectively. This can be attributed to the slightly larger steric demand of the ethyl group compared to a methyl group.

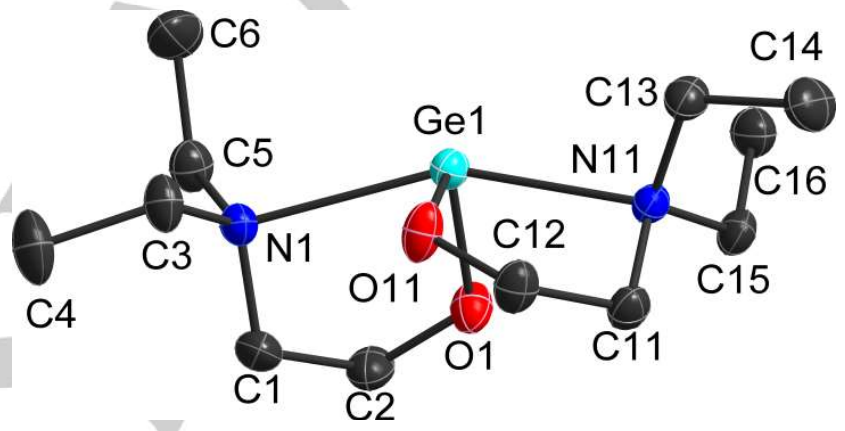

Figure 1. Solid state structure of $\mathbf{1} ; \mathrm{H}$-atoms have been omitted for clarity and displacement ellipsoids are drawn at the $50 \%$ probability levels. Selected bond lengths $[\AA]$ and angles [ $\left.{ }^{\circ}\right]$ : $\mathrm{Ge}(1)-\mathrm{O}(1)$ 1.8593(11), $\mathrm{Ge}(1)-\mathrm{O}(11)$ 1.8608(11), $\mathrm{Ge}(1)-\mathrm{N}(11)$ 2.3595(12), ), Ge(1)-N(1) 2.4331(12), O(1)-Ge(1)-O(11) 99.29(6), $\mathrm{O}(1)-\mathrm{Ge}(1)-\mathrm{N}(11) \quad 83.69(5), \quad \mathrm{O}(1)-\mathrm{Ge}(1)-\mathrm{N}(1) \quad 80.05(5), \quad \mathrm{O}(11)-\mathrm{Ge}(1)-\mathrm{N}(1)$ 83.16(4), O(11)-Ge(1)-N(11) 79.30(5N(11)-Ge(1)-N(1) 153.76(4).

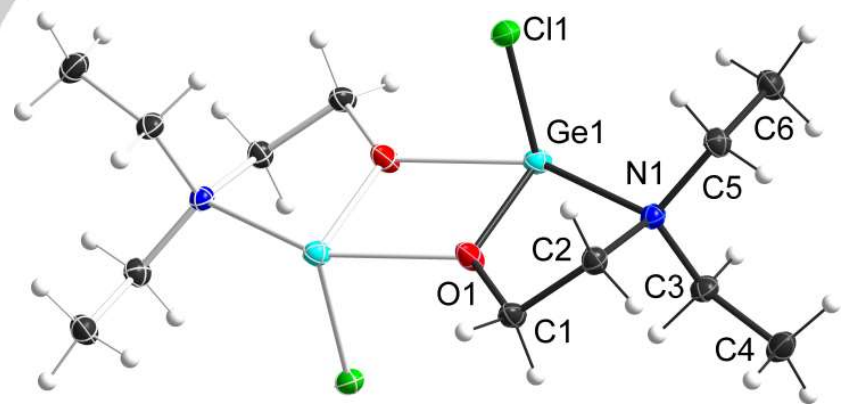

Figure 2. Solid state structure of 4; Displacement ellipsoids are drawn at the $50 \%$ probability levels. The light colored parts of the molecule are generated by symmetry $(\# 1-x, 1-y, 1-z)$. Selected bond lengths $[\AA]$ and angles $\left[{ }^{\circ}\right]$ : $\mathrm{Ge}(1)-$ $\mathrm{O}(1)$ 1.8790(16), Ge(1)-O(1)\#1 2.2191(16), Ge(1)-Cl(1) 2.3163(5), Ge(1)-N(1) 2.3279(17), O(1)-Ge(1)-O(1)\#1 70.29(7), O(1)-Ge(1)-Cl(1) 97.93(6), O(1)\#1$\mathrm{Ge}(1)-\mathrm{Cl}(1)$ 87.96(5), O(1)-Ge(1)-N(1) 78.36(6), O(1)\#1-Ge(1)-N(1) 147.91(6), $\mathrm{Cl}(1)-\mathrm{Ge}(1)-\mathrm{N}(1)$ 89.76(4).

In 4, the bond length of the inner coordination sphere (Ge1-Cl1, Ge1-O1) are also comparable to those observed for $\mathrm{Ge}\left(\mathrm{N}_{3}\right) \mathrm{OC}_{2} \mathrm{H}_{4} \mathrm{NMe}_{2}$. The $\mathrm{Ge}-\mathrm{O}$ bonds are - within standard 


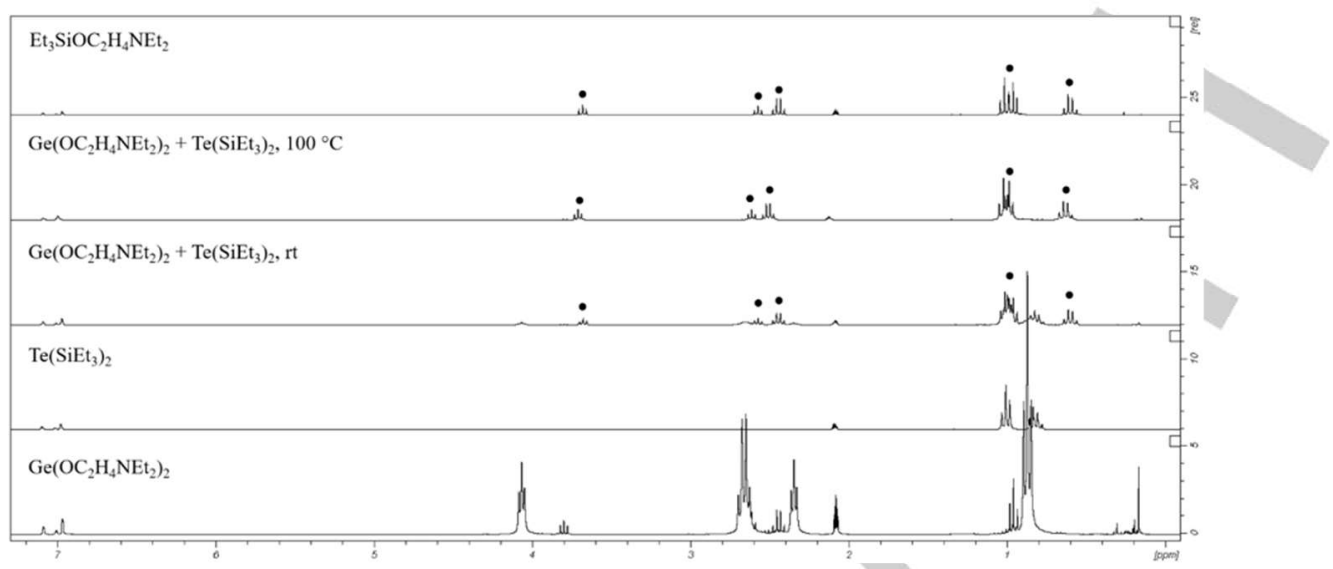

Figure 3. ${ }^{1} \mathrm{H}-\mathrm{NMR}$ spectra of $\mathrm{Ge}\left(\mathrm{OC}_{2} \mathrm{H}_{4} \mathrm{NMe}_{2}\right)_{2}$, $\left(\mathrm{Et}_{3} \mathrm{Si}\right)_{2} \mathrm{Te}$ and $\mathrm{Et}_{3} \mathrm{SiOC}_{2} \mathrm{H}_{4} \mathrm{NEt}_{2}$ and temperature-dependent ${ }^{1} \mathrm{H}-\mathrm{NMR}$ spectra of the reaction of $\mathrm{Ge}\left(\mathrm{OC}{ }_{2} \mathrm{H}_{4} \mathrm{NMe}_{2}\right)_{2}$ with $\left(\mathrm{Et}_{3} \mathrm{Si}\right)_{2} \mathrm{Te}$ in toluene- $\mathrm{d}_{8}$. Marked resonances correspond to those of the silylether $\mathrm{Et}_{3} \mathrm{SiOC}_{2} \mathrm{H}_{4} \mathrm{NMe}_{2}$

uncertainties - of equal length and the Ge-Cl [2.3163(5) $\AA$ ] and $\mathrm{Ge}-\mathrm{N}_{\text {azide }}[2.220(4) \AA]$ both exceed the sum of the covalent radii. The $\mathrm{Ge}-\mathrm{O}$ bond in the outer co-ordination sphere of 4 $[2.2191(16) \AA]$ is roughly $12 \mathrm{pm}$ shorter than that of $\mathrm{Ge}\left(\mathrm{N}_{3}\right) \mathrm{OC}_{2} \mathrm{H}_{4} \mathrm{NMe}_{2}[2.338(3) \AA]$, while the $\mathrm{Ge}-\mathrm{N}$ bond of 4 is approximately $10 \mathrm{pm}$ longer $[2.3279(17)$ vs. $(2.220(4) \AA]$ respectively. These findings most likely result from both steric and electronic differences between $\mathrm{N}_{3}{ }^{-}$and $\mathrm{Cl}^{-}$anions. In terms of the VSEPR model, the coordination of the $\mathrm{Ge}$ can be described as distorted trigonal-bipyramidal with the free electron pair occupying the third equatorial position.

\section{Synthesis of ME (M = Ge, Sn, Pb; E = S, Se, Te)}

Binary as well as ternary group 14 metal chalcogenides have been synthesized by various methods including solid state reactions as well as by controlled reactions of suitable precursors and by thermal decomposition of metal organic single source precursors in solution ${ }^{[23]}$ and their synthesis has been frequently reviewed. ${ }^{[24]}$ Among other, diorganyl dichalcogenides have been demonstrated to be of particular interest as useful synthons for the synthesis of colloidal semiconducting nanocrystals. ${ }^{[25]}$ We herein synthesized $\mathrm{ME}$ particles at moderate temperatures $\left(140-180^{\circ} \mathrm{C}\right)$ by scrambling reactions of $\mathrm{M}\left(\mathrm{OC}_{2} \mathrm{H}_{4} \mathrm{NMe}_{2}\right)_{2}$ with $\left(\mathrm{Me}_{3} \mathrm{Si}\right)_{2} \mathrm{~S}$, $\left(\mathrm{Et}_{3} \mathrm{Si}\right)_{2} \mathrm{Se}$ and $\left(\mathrm{Et}_{3} \mathrm{Si}\right)_{2} \mathrm{Te}$, respectively, in di-isopropylbenzene (DIPB) under inert gas conditions in a glovebox (hot injection method). The reactions proceeded with elimination of the corresponding silylether and subsequent formation of the corresponding IV-VI materials in almost quantitative yields. The particles were isolated by centrifugation and purified by several washing steps with methanol $(3 x)$ and $n$-hexane (1x). Capping agents such as polyvinylpyrrolidone (PVP), oleylamine, trioctylphosphine (TOP) or trioctylphosphine oxide (TOPO), which are typically used in the synthesis of nanoparticles due to their capability to serve as shape and size-controlling agent and also to prevent the nanoparticles from agglomeration, were not used since we were interested in the synthesis of pure "naked" materials without organic stabilizers on the surface.

$$
\begin{gathered}
\mathrm{M}\left(\mathrm{OC}_{2} \mathrm{H}_{4} \mathrm{NR}_{2}\right)_{2} \frac{\mathrm{E}\left(\mathrm{SiR}_{3}\right)_{2}}{-\mathrm{R}_{3} \mathrm{SiOC}_{2} \mathrm{H}_{4} \mathrm{NR}_{2}} \mathrm{ME} \\
\mathrm{M}=\mathrm{Ge}, \mathrm{Sn}, \mathrm{Pb} ; \mathrm{E}=\mathrm{S}, \mathrm{Se}, \mathrm{Te}
\end{gathered}
$$

Scheme 2. Synthesis of ME nanoparticles $(M=G e, S n, P b ; E=S, S e, T e)$.

Temperature-dependent in situ ${ }^{1} \mathrm{H}$ NMR studies of the reaction of 1 with $\left(\mathrm{Et}_{3} \mathrm{Si}\right)_{2} \mathrm{Te}$ (Fig. 3) and 2 with $\left(\mathrm{Et}_{3} \mathrm{Si}\right)_{2} \mathrm{Se}$ (Fig. S2) showed that both reactions proceeded with immediate formation - even at ambient temperature - of the expected silylethers $\mathrm{Et}_{3} \mathrm{SiOC}_{2} \mathrm{H}_{4} \mathrm{NEt}_{2}$ and $\mathrm{Et}_{3} \mathrm{SiOC}_{2} \mathrm{H}_{4} \mathrm{NMe}_{2}$, respectively. However, higher reaction temperatures are necessary to obtain crystalline materials in a reasonable amount of time.

FT-IR spectra of the materials showed small adsorption bands due to $\mathrm{CH}$-stretching vibrations in the typical region between 2800 and $3000 \mathrm{~cm}^{-1}$, proving that the surface of the nanoparticles contains a small organic layer most likely due to adsorbed solvent molecules. A representative IR spectrum of SnTe is shown in the electronic supplement (Fig. S24).

The black solids obtained from the nine different thermolysis reactions are crystalline as was shown by PXRD with exception of $\mathrm{GeS}$ and $\mathrm{GeSe}$, which are rather amorphous. Therefore, these two samples were annealed at $400{ }^{\circ} \mathrm{C}$ for $20 \mathrm{~h}$, yielding crystalline $\mathrm{GeS}$ and $\mathrm{GeSe}$ materials as was proven by PXRD. Fig. 4 exemplarily shows the PXRDs of the GeTe, SnSe, SnTe and $\mathrm{PbTe}$ powders, while those of the remaining chalcogenide materials are given in the electronic supplement (Figs. S4-S23). The PXRD of GeTe showed additional reflections due to elemental Te as was previously observed. ${ }^{[11]}$ 
Table 1. Lattice parameters, density and crystallite size of as-synthesized $\mathrm{GeE}$, $\mathrm{SnE}$ and PbE phases as determined by the Rietveld refinement.

\begin{tabular}{|c|c|c|c|c|c|c|}
\hline Phases / ICSD-no. & & Lattice parameters & & & Density & Crystallite size \\
\hline & & $\mathrm{a}(\AA)$ & $\mathrm{b}(\AA)$ & $c(\AA)$ & $\rho\left(\mathrm{g} / \mathrm{cm}^{3}\right)$ & $\mathrm{D}(\mathrm{nm})$ \\
\hline GeS (Pbnm) / & Lit. & $4.299(4)$ & $3.646(4)$ & $10.481(9)$ & 4.23 & \\
\hline ICSD-1256 & calcd. & $4.2947(1)$ & $3.6431(1)$ & $10.4749(2)$ & 4.24 & $106(7)$ \\
\hline GeSe $(P b n m) /$ & Lit. & $4.388(4)$ & $3.833(4)$ & $10.825(9)$ & 5.53 & \\
\hline ICSD-41738 & calcd. & $4.3874(7)$ & $3.8403(7)$ & $10.8384(2)$ & 5.51 & $17(0)$ \\
\hline GeTe $(R 3-m H) /$ & Lit. & $4.156(3)$ & & $10.663(5)$ & 6.25 & \\
\hline ICSD-188458 & calcd. & $4.1822(3)$ & & $10.6459(7)$ & 6.19 & $127(9)$ \\
\hline SnS $(P b n m) /$ & Lit. & $4.334(1)$ & $3.987(1)$ & $11.200(2)$ & 5.17 & \\
\hline ICSD-41739 & calcd. & $4.2724(3)$ & $4.0120(3)$ & $11.2404(6)$ & 5.19 & $45(3)$ \\
\hline SnSe $(P b n m) /$ & Lit. & $4.445(1)$ & $4.153(1)$ & $11.501(2)$ & 6.12 & \\
\hline ICSD-41740 & calcd. & $4.3891(2)$ & $4.2179(1)$ & $11.5903(3)$ & 6.12 & $10(2)$ \\
\hline $\operatorname{SnTe}(F m-3 m) /$ & Lit. & $6.318(3)$ & & & 6.49 & \\
\hline ICSD-188457 & calcd. & $6.3226(1)$ & & & 6.44 & $142(3)$ \\
\hline $\mathrm{PbS}(F m-3 m) /$ & Lit. & $5.934(1)$ & & & 7.61 & \\
\hline ICSD-38293 & calcd. & $5.9349(1)$ & & & 7.60 & $35(2)$ \\
\hline $\mathrm{PbSe}(F m-3 m) /$ & Lit. & $6.128(1)$ & & & 8.26 & \\
\hline ICSD-38294 & calcd. & $6.1243(0)$ & & & 8.27 & $21(1)$ \\
\hline $\operatorname{PbTe}(F m-3 m) /$ & Lit. & $6.462(1)$ & & & 8.24 & \\
\hline ICSD-38295 & calcd. & $6.4598(1)$ & & & 8.25 & $5.2(2)$ \\
\hline
\end{tabular}
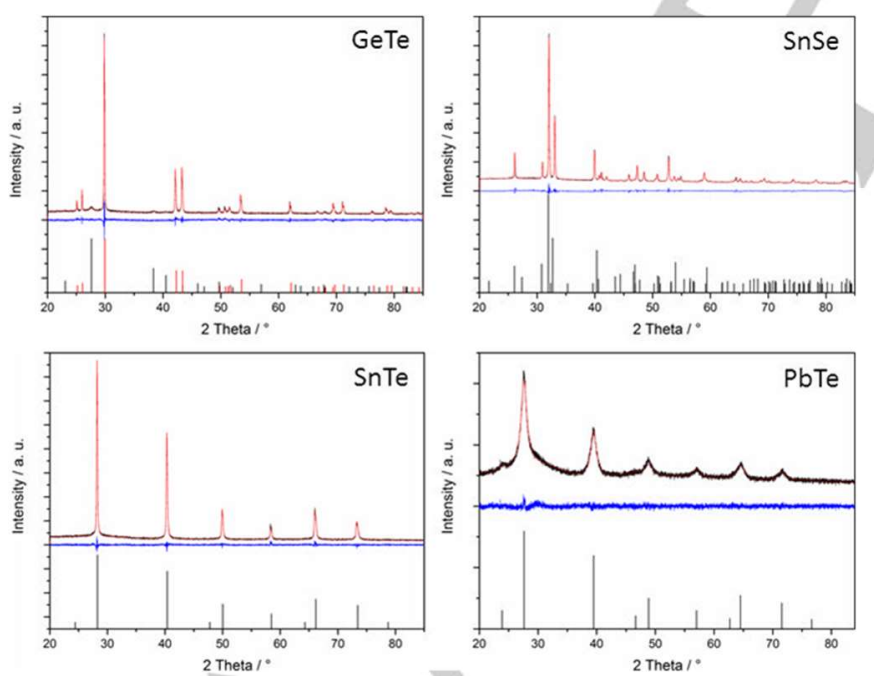

Figure 4. Rietveld plots of annealed $\mathrm{GeTe}, \mathrm{SnSe}, \mathrm{SnTe}$ and $\mathrm{PbTe}$ powders as obtained by reaction of 1 and 2 with $\left(\mathrm{Et}_{3} \mathrm{Si}\right)_{2} \mathrm{E}(\mathrm{E}=\mathrm{Se}, \mathrm{Te})$ at $170{ }^{\circ} \mathrm{C}$ (experimental (black), calculated (red) and difference pattern (blue)) Reference peak positions are given as vertical bars.
Table 2. EDX results of the ME particles.

\begin{tabular}{lll}
\hline Material & M [at\%][a] & $E[a t \%][b]$ \\
\hline GeS & $49.7(3)$ & $50.3(1)$ \\
GeSe & $50.7(4)$ & $49.3(6)$ \\
$\mathrm{GeTe}$ & $49.3(3)$ & $50.7(8)$ \\
$\mathrm{SnS}$ & $50.8(9)$ & $49.2(2)$ \\
$\mathrm{SnSe}$ & $49.1(8)$ & $50.9(4)$ \\
$\mathrm{SnTe}$ & $49.1(8)$ & $50.9(9)$ \\
$\mathrm{PbS}$ & $51.6(4)$ & $48.4(1)$ \\
$\mathrm{PbSe}$ & $51.7(9)$ & $48.3(2)$ \\
$\mathrm{PbTe}$ & $50.8(8)$ & $49.2(4)$ \\
\hline
\end{tabular}

${ }^{\left[{ }^{a]} \mathrm{M}\right.}=\mathrm{Ge}, \mathrm{Sn}, \mathrm{Pb} ;{ }^{[\mathrm{b}]} \mathrm{E}=\mathrm{S}, \mathrm{Se}, \mathrm{Te}$

All Bragg reflections with a significant intensity can be indexed based on the structures of orthorhombic GeS, GeSe, SnSe, SnS as well as rhombohedral GeTe and cubic SnTe, PbS, PbSe and $\mathrm{PbTe}$. The crystallographic density of the materials was calculated by Rietveld refinement (table 1). The calculated lattice parameters are in a very good agreement with the ICSD 
database files for the pure ME phases. Based on the PXRD studies, the formation of crystalline group 14-chalcogenide materials can be concluded. The chemical composition of the materials was further analyzed by EDX, showing the formation of stoichiometric materials (table 2).

SEM studies. The nine powders obtained from precursors 1 - 3 are highly inhomogeneous particles concerning their size and shape. However, this is not surprising since capping agents which are typically used for the size and shape-selective synthesis of these type of materials, havn't been used. The focus of this study was clearly on the synthesis of phase-pure materials in order to prove the potential capability of $1-3$ to serve as alternate precursors for the synthesis of $M E(M=G e$, $\mathrm{Sn}, \mathrm{Pb} ; \mathrm{E}=\mathrm{S}, \mathrm{Se}, \mathrm{Te}$ ) materials rather than on the synthesis of well-defined nanoparticles with homogeneous morphology. However, the general morphologies observed herein have been previously reported for these types of materials. ${ }^{[26]}$
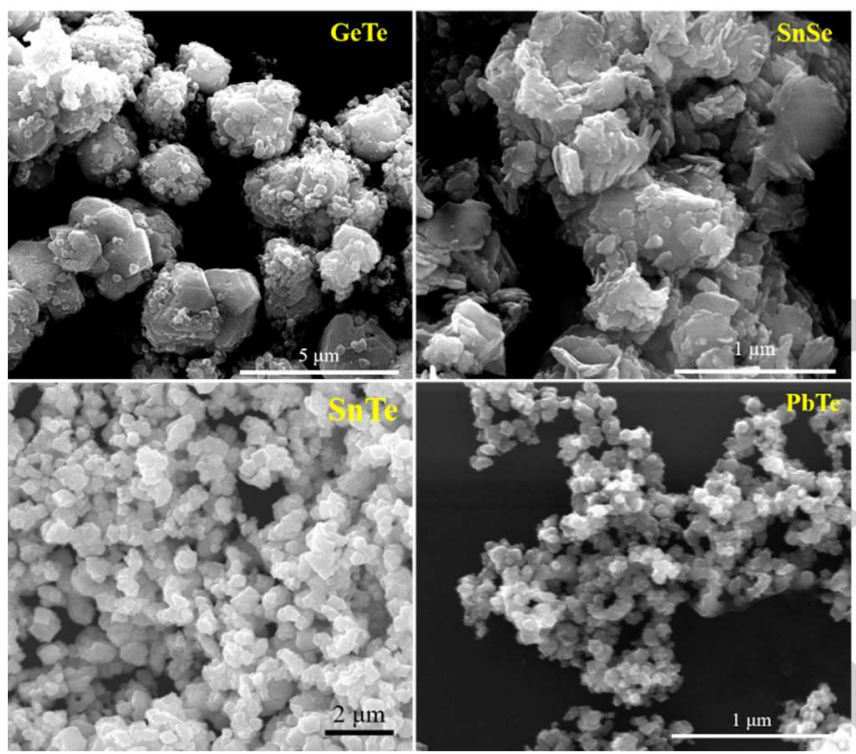

Figure 6. SEM photographs of $\mathrm{GeTe}, \mathrm{SnSe}, \mathrm{SnTe}$ and $\mathrm{PbTe}$ as-obtained from the reactions of $\mathbf{1}-\mathbf{3}$ and $\left(\mathrm{Et}_{3} \mathrm{Si}\right)_{2} \mathrm{E}(\mathrm{E}=\mathrm{Se}, \mathrm{Te})$ in $\mathrm{DIPB}$ at elevated temperatures.

\section{Conclusions}

Crystalline germanium, tin and lead chalcogenide nanoparticles were obtained by reaction of the new intermolecular-stabilized, homoleptic metal alkoxide precursors $\mathrm{Ge}\left(\mathrm{OCH}_{2} \mathrm{CH}_{2} \mathrm{NEt}_{2}\right)_{2}$ 1, whose solid state structure was determined by single crystal $\mathrm{X}$ ray diffraction, $\mathrm{Sn}\left(\mathrm{OCH}_{2} \mathrm{CH}_{2} \mathrm{NMe}_{2}\right)_{2} 2$ and $\mathrm{Pb}\left(\mathrm{OCH}_{2} \mathrm{CH}_{2} \mathrm{NMe}_{2}\right)_{2} 3$ with $\left(\mathrm{Me}_{3} \mathrm{Si}\right)_{2} \mathrm{~S}$ and $\left(\mathrm{Et}_{3} \mathrm{Si}\right)_{2} \mathrm{E}(\mathrm{E}=\mathrm{Se}, \mathrm{Te})$ at moderate temperatures. The inhomogeneous size and morphology of the powders was proven by SEM, while EDX and XRD revealed the stoichiometric chemical composition of the crystalline nanomaterials. Minor carbon and oxygen impurities due to the presence of remaining solvent and surface oxidation were observed by IR and EDX.

\section{Experimental Section}

Materials. 1,3-diisopropylbenzene (DIPB, Sigma-Aldrich) was carefully dried over $\mathrm{Na} / \mathrm{K}$ alloy and degassed prior to use and $\mathrm{Et}_{2} \mathrm{NC}_{2} \mathrm{H}_{4} \mathrm{OH}$ was dried for $2 \mathrm{~d}$ over magnesium cuttings and distilled. $\mathrm{Et}_{2} \mathrm{O}$ and $n$-hexane were dried by a solvent purification system (MBraun) and degassed prior to use. $\mathrm{CH}_{2} \mathrm{Cl}_{2}$ was refluxed over $\mathrm{CaH}_{2}$ for several days and distilled prior to use. $\mathrm{Ge}\left(\mathrm{OC}_{2} \mathrm{H}_{4} \mathrm{NEt}_{2}\right)_{2}$ (1), $\mathrm{Sn}\left(\mathrm{OC}_{2} \mathrm{H}_{4} \mathrm{NMe}_{2}\right)_{2}$ (2), and $\mathrm{Pb}\left(\mathrm{OC}_{2} \mathrm{H}_{4} \mathrm{NMe}_{2}\right)_{2}$ (3) were prepared by a slightly modified route, ${ }^{[27]}$ while $\mathrm{E}\left(\mathrm{SiMe}_{3}\right)_{2}(\mathrm{E}=\mathrm{S}$, $\mathrm{Se}, \mathrm{Te})$ were synthesized according to literature methods. ${ }^{[28]}$ All synthetic steps were performed under an argon atmosphere using standard Schlenk techniques and the nanoparticle synthesis was performed in the glovebox under inert conditions.

$\mathrm{Ge}\left(\mathrm{OC}_{2} \mathrm{H}_{4} \mathrm{NEt}_{2}\right)_{2}$ 1. $3.76 \mathrm{~g}$ (16.2 mmol) of $\mathrm{GeCl}_{2} \cdot$ dioxan were suspended in $80 \mathrm{~mL}$ of $\mathrm{Et}_{2} \mathrm{O}$ at ambient temperature and dropwise treated with $60 \mathrm{~m}$ of a $\mathrm{LiOC}_{2} \mathrm{H}_{4} \mathrm{NEt}_{2}$ solution $(4 \mathrm{~g}, 32.00 \mathrm{mmol}$ ). The resulting light yellow suspension was stirred for additional $12 \mathrm{~h}$. The solvent was removed in vacuum and the residue re-suspended in $40 \mathrm{~mL}$ of $n$-hexane, filtered through celite and extracted two times with $20 \mathrm{~mL}$ of $n$-hexane. After removal of the solvent in vacuum, a yellow oily liquid ( $88 \%$ yield, $4.35 \mathrm{~g}$, $14.26 \mathrm{mmol}$ ) was obtained, which was purified by distillation in vacuum at $160{ }^{\circ} \mathrm{C} . \mathrm{C}_{12} \mathrm{H}_{28} \mathrm{GeN}_{2} \mathrm{O}_{2}(\mathrm{M}=305.00 \mathrm{~g} / \mathrm{mol})$ : calcd. C 47.53, H 9.41, N 8.17; found C 47.85, H 9.60, N 8.29. ${ }^{1} \mathrm{H}-\mathrm{NMR}(300 \mathrm{MHz}$, tol-d, $298 \mathrm{~K}$ ): $\delta$ $=0.87\left(\mathrm{t},{ }^{3} \mathrm{~J}_{\mathrm{HH}}=7.2 \mathrm{~Hz}, 12 \mathrm{H}, \mathrm{CH}_{3} \mathrm{CH}_{2}\right), 2.35\left(\mathrm{t},{ }^{3} \mathrm{~J}_{\mathrm{HH}}=5.6 \mathrm{~Hz}, 4 \mathrm{H}, \mathrm{CH}_{2} \mathrm{~N}\right)$, $2.66\left(\mathrm{q},{ }^{3} \mathrm{~J}_{\mathrm{HH}}=7.2 \mathrm{~Hz}, 8 \mathrm{H}, \mathrm{CH}_{3} \mathrm{CH}_{2}\right), 4.07\left(\mathrm{t},{ }^{3} \mathrm{~J}_{\mathrm{HH}}=5.3 \mathrm{~Hz}, 4 \mathrm{H}, \mathrm{CH}_{2} \mathrm{O}\right)$. ${ }^{13} \mathrm{C}-\mathrm{NMR}(75 \mathrm{MHz}$, tol-d $8,298 \mathrm{~K}): \delta=9.3\left(\mathrm{CH}_{3} \mathrm{CH}_{2}\right), 43.8\left(\mathrm{CH}_{3} \mathrm{CH}_{2}\right), 55.6$ $\left(\mathrm{CH}_{2} \mathrm{~N}\right), 63.3\left(\mathrm{CH}_{2} \mathrm{O}\right) . \mathrm{IR} \mathrm{v}=2969,2936,2873,2838,2687,1648,1459$, $1375,1256,1190,1175,1083,1052,1000,974,917,878,799,729$. In addition, few single crystals of $\mathbf{4}$ were isolated as side-product in very low yield $(4 \%)$ in the distillation flask.

$\mathrm{Sn}\left(\mathrm{OC}_{2} \mathrm{H}_{4} \mathrm{NMe}_{2}\right)_{2}$ 2. $5.63 \mathrm{~g}(29.71 \mathrm{mmol}) \mathrm{SnCl}_{2}$ were suspended in 70 $\mathrm{mL}$ of $\mathrm{Et}_{2} \mathrm{O}$, cooled to $0{ }^{\circ} \mathrm{C}$ and then combined with a suspension of 5.65 $\mathrm{g}(59.43 \mathrm{mmol})$ of $\mathrm{LiOC}_{2} \mathrm{H}_{4} \mathrm{NMe}_{2}$ in $60 \mathrm{~mL}$ of $\mathrm{Et}_{2} \mathrm{O}$. After stirring for $12 \mathrm{~h}$ at ambient temperature, the solvent was removed from the white suspension in vacuum, the resulting residue re-suspended in $20 \mathrm{~mL}$ of dichloromethane and extracted twice with the same amount of solvent.

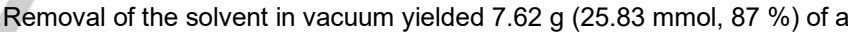
white solid. ${ }^{1} \mathrm{H}-\mathrm{NMR}\left(300 \mathrm{MHz}, \mathrm{C}_{6} \mathrm{D}_{6}, 298 \mathrm{~K}\right): \delta=2.09\left(\mathrm{br}, 12 \mathrm{H}, \mathrm{NCH}_{3}\right)$, 2.35 (br, $\left.4 \mathrm{H}, \mathrm{NCH}_{2}\right), 3.93\left(\mathrm{br}, 4 \mathrm{H}, \mathrm{OCH}_{2}\right)$.

$\mathrm{Pb}\left(\mathrm{OC}_{2} \mathrm{H}_{4} \mathrm{NMe}_{2}\right)_{2}$ 3. $1.58 \mathrm{~g}$ (5.68 mmol) $\mathrm{PbCl}_{2}$ were suspended in $20 \mathrm{~mL}$ of $\mathrm{Et}_{2} \mathrm{O}$, cooled to $0{ }^{\circ} \mathrm{C}$ and treated with a suspension of $1.08 \mathrm{~g} \mathrm{(11.36}$ $\mathrm{mmol}$ ) of $\mathrm{LiOC}_{2} \mathrm{H}_{4} \mathrm{NMe}_{2}$ in $10 \mathrm{~mL}$ of $\mathrm{Et}_{2} \mathrm{O}$. After stirring for $12 \mathrm{~h}$ at ambient temperature, the solvent was removed in vacuum and the residue was re-suspended in $20 \mathrm{~mL}$ of $\mathrm{CH}_{2} \mathrm{Cl}_{2}$ and extracted twice with the same amount of $\mathrm{CH}_{2} \mathrm{Cl}_{2}$. After removal of the solvent of the combined extracts, $1.78 \mathrm{~g}(4.64 \mathrm{mmol}, 82 \%)$ of a white solid were obtained. ${ }^{1} \mathrm{H}$ $\operatorname{NMR}\left(300 \mathrm{MHz}, \mathrm{C}_{6} \mathrm{D}_{6}, 298 \mathrm{~K}\right): \delta=2.17\left(\mathrm{~s}, 12 \mathrm{H}, \mathrm{NCH}_{3}\right), 2.58\left(\mathrm{t},{ }^{3} \mathrm{~J}_{\mathrm{HH}}=\right.$ $\left.5.1 \mathrm{~Hz}, 4 \mathrm{H}, \mathrm{NCH}_{2}\right), 4.83\left(\mathrm{t},{ }^{3} \mathrm{~J}_{\mathrm{HH}}=4.9 \mathrm{~Hz}, 4 \mathrm{H}, \mathrm{OCH}_{2}\right)$.

Single crystal X-ray diffraction. Crystallographic data of 1 and $\mathbf{4}$ were collected on a Bruker D8 Kappa APEX2 diffractometer $\left(\mathrm{MoK}_{\alpha}\right.$ radiation, $\lambda$ $=0.71073 \AA)$ at $100(1) \mathrm{K}(\mathbf{1})$ and $183(1) \mathrm{K}(\mathbf{4}): \mathbf{G e}\left(\mathbf{O C}_{2} \mathbf{H}_{4} \mathbf{N E t}_{2}\right)_{2} \mathbf{1}: M=$ 304.95 , colorless crystal, $(0.300 \times 0.300 \times 0.300 \mathrm{~mm})$; monoclinic, space group $P 21 / c ; a=6.5259(4) \AA, b=23.6526(14) \AA, c=9.9248(6) \AA ; \alpha=90^{\circ}$, $\beta=90.635(2)^{\circ}, \gamma=90^{\circ}, V=1531.84(16) \AA^{3} ; Z=4 ; \mu=1.995 \mathrm{~mm}^{-1} ; \rho_{\text {calc }}=$ $1.322 \mathrm{~g} \cdot \mathrm{cm}^{-3} ; 33660$ reflexes $\left(\theta_{\max }=25.242^{\circ}\right), 3921$ unique $\left(R_{\mathrm{int}}=\right.$ $0.0313) ; 154$ parameters; largest $\max . / \mathrm{min}$ in the final difference Fourier synthesis $0.401 \mathrm{e} \cdot \AA^{-3} /-0.424 \mathrm{e} \cdot \AA^{-3}$; max./min. transmission $0.30 / 0.75 ; R_{1}$ $=0.0252(\mathrm{I}>2 \sigma(\mathrm{I})), w R_{2}=0.0617$ (all data). $\mathbf{G e}\left(\mathbf{O C}_{2} \mathrm{H}_{4} \mathrm{NEt}_{2}\right)_{2} \mathbf{4}: M=$ 448.44 , orange crystal, $(0.340 \times 0.175 \times 0.114 \mathrm{~mm})$; triclinic, space 
group $P-1 ; a=7.1825(4) \AA, b=7.3054(4) \AA, c=10.5121(5) \AA ; \alpha=$ $71.418(2)^{\circ}, \beta=80.726(2)^{\circ}, y=60.650(2)^{\circ}, V=455.71(4) \AA^{3} ; Z=1 ; \mu=$

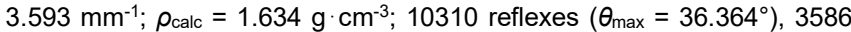
unique $\left(R_{\text {int }}=0.0198\right) ; 93$ parameters; largest $\max . / \min$ in the final difference Fourier synthesis 1.776 e. $\AA^{-3 /} \quad-0.747$ e. $\AA^{-3}$; max./min. transmission 0.52/0.75; $R_{1}=0.0307(\mathrm{I}>2 \sigma(\mathrm{I})), w R_{2}=0.0874$ (all data). The structures were solved by Direct Methods (SHELXS-97) ${ }^{[29]}$ and refined anisotropically by full-matrix least-squares on $F^{2}$ (SHELXL2014). ${ }^{[30]}$ Absorption correction was performed semi-empirically from equivalent reflections on basis of multi-scans (Bruker AXS APEX2). Hydrogen atoms were refined using a riding model or rigid methyl groups. The crystal of 1 was grown at a temperature of $250 \mathrm{~K}$ by an in-situ zone melting process inside a quartz capillary using focused infrared-laserradiation. ${ }^{[18]}$ The experimental setup does only allow for $\omega$ scans with $\kappa$ set to $0^{\circ}$. Any other orientation would have partially removed the capillary from the cooling steam and thus led to a melting of the crystals. This limits the completeness to $65 \%$ to $90 \%$ depending on the crystal system.

The crystallographic data (without structure factors) were deposited as „supplementary publication no. CCDC-1508695 (1) and CCDC-1508696 (4) at the Cambridge Crystallographic Data Centre. These data can be obtained free of charge from The Cambridge Crystallographic Data Centre: CCDC, 12 Union Road, Cambridge, CB21EZ (Fax: (+44)1223/336033; E-mail: deposit@ccdc.cam-ak.uk).

\section{Nanoparticle Synthesis}

GeS/GeSe/GeTe: A solution of $100 \mathrm{mg}(0.33 \mathrm{mmol})$ of 1 in $5 \mathrm{~mL}$ of DIPB was heated to $140{ }^{\circ} \mathrm{C}$ and $\left(\mathrm{E}\left(\mathrm{SiEt}_{3}\right)_{2}(\mathrm{E}=\mathrm{S} 58.50 \mathrm{mg}, 0.33 \mathrm{mmol}\right.$; Se $101.48 \mathrm{mg}, 0.33 \mathrm{mmol}$; Te $117.42 \mathrm{mg}, 0.33 \mathrm{mmol}$ ) was quickly injected. The solutions, which immediately turned black or dark brown, were heated for additional $10 \mathrm{~h}$ at $180{ }^{\circ} \mathrm{C}$. The resulting suspension was cooled to ambient temperature and the solid residues isolated by centrifugation and washed several with methanol (3x) and $n$-hexane (1x). The isolated $\mathrm{GeS}$ and $\mathrm{GeSe}$ samples were annealed for $20 \mathrm{~h}$ at $400{ }^{\circ} \mathrm{C}$ in evacuated glass ampoules.

SnS/SnSe/SnTe: $100 \mathrm{mg}(0.34 \mathrm{mmol})$ of 2 were dissolved in $5 \mathrm{~mL}$ of DIPB at $100{ }^{\circ} \mathrm{C}$ and $60.49 \mathrm{mg}(0.34 \mathrm{mmol})$ of $4,104.93 \mathrm{mg}(0.34 \mathrm{mmol})$ of $\mathbf{5}$ or $121.42 \mathrm{mg}(0.34 \mathrm{mmol})$ of $\mathbf{6}$ were quickly added, whereupon the solutions immediately turned black and black precipitates formed. The suspension was heated for additional $4 \mathrm{~h}$ at $100{ }^{\circ} \mathrm{C}$. The solids were isolated by centrifugation and purified by several washing steps with methanol (3x) and $n$-hexane (1x)

PbS/PbSe/PbTe: $100 \mathrm{mg}(0.26 \mathrm{mmol})$ of 3 were dissolved in $5 \mathrm{~mL}$ of DIPB at $100{ }^{\circ} \mathrm{C} .46 .53 \mathrm{mg}(0.26 \mathrm{mmol})$ of $4,78.66 \mathrm{mg}(0.26 \mathrm{mmol})$ of 5 or $93.40 \mathrm{mg}(0.26 \mathrm{mmol})$ of 6 were quickly injected, whereupon the solutions turned black and black precipitates formed. The suspensions were heated at $100{ }^{\circ} \mathrm{C}$ for $3 \mathrm{~h}$ and the resulting solids were isolated by centrifugation and purified by several washing steps with methanol $(3 \mathrm{x})$ and $n$-hexane $(1 \mathrm{x})$.

NMR spectra. ${ }^{1} \mathrm{H}(300 \mathrm{MHz})$ and ${ }^{13} \mathrm{C}\left\{{ }^{1} \mathrm{H}\right\}(75.5 \mathrm{MHz})$ NMR spectra $(\delta$ in ppm) were recorded using a Bruker Avance DPX-300 spectrometer and were referenced to internal $\mathrm{C}_{6} \mathrm{D}_{5} \mathrm{H}\left({ }^{1} \mathrm{H}: \delta=7.154 ;{ }^{13} \mathrm{C}: \delta=128.39\right)$ and $\mathrm{C}_{6} \mathrm{D}_{5} \mathrm{CHD}_{2}\left({ }^{1} \mathrm{H}: \delta=2.09 ;{ }^{13} \mathrm{C}: \delta=20.40\right)$.

IR spectra. IR spectra were recorded in a glovebox using an ALPHA-T FT-IR spectrometer equipped with a single reflection ATR sampling module.
SEM and EDX Analysis. SEM studies were carried out on an ESEM Quanta 400 FEG and a Jeol JSM 6510 equipped with an energy dispersive X-ray spectroscopy (EDX) device (Bruker Quantax 400).

X-ray Analysis. PXRD patterns were obtained using a Bruker D8 Advance powder diffractometer with $\mathrm{Cu}$ Ka radiation $(\lambda: 1.5418 \AA$, $40 \mathrm{kV}$ and $40 \mathrm{~mA}$ ) using a silicon single crystal as sample holder to minimize scattering. The powders were re-dispersed in ethanol on the silicon surface for better homogenization and then investigated in the range from 10 to $90^{\circ} 2 \theta$ with a step size of $0.01^{\circ} 2 \theta$ with a counting time of 0.6 s. Rietveld refinement was performed with the program package TOPAS 5.0 (Bruker) to determine the lattice parameters and average crystallite size by use of the Scherrer equation ${ }^{[31]}$ with the program package TOPAS 5.0 (Bruker). The background was modelled using Chebyshev polynomials. The structure models of GeS (\#1256), GeSe (\#41738), GeTe (\#188458), SnS (\#41739), SnSe (\#41740), SnTe (\#188457), PbS (\#38293), PbSe (\#38294) and PbTe (\#38295) from the ICSD database were used. For each Rietveld refinement, the instrumental correction as determined with a standard powder sample from NIST (National Institute of Standards and Technology) as standard reference material (SRM $660 \mathrm{~b} ; \mathrm{a}\left(\mathrm{LaB}_{6}\right)=4.15689 \AA$ ) was taken into account.

Supporting Information. Cif files of $\mathbf{1}$ and $\mathbf{4}$, temperature-dependent ${ }^{1} \mathrm{H}$ NMR studies of $\mathbf{1}$ and of the reaction of $\mathbf{2}$ and $\left(\mathrm{Et}_{3} \mathrm{Si}\right)_{2} \mathrm{Se}$ in toluene- $\mathrm{d}_{8}$ PXRDs and Rietveld refinements of $\mathrm{GeE}, \mathrm{SnE}$ and $\mathrm{PbE}(\mathrm{E}=\mathrm{S}, \mathrm{Se}, \mathrm{Te})$ as well as FT-IR spectrum of SnTe are given in the electronic supplement.

\section{Acknowledgements}

S. Schulz gratefully acknowledges financial support by the Deutsche Forschungsgemeinschaft (DFG) within the priority program SPP 1708 (SCHU 1069/17-1) and the University of Duisburg-Essen.

Keywords: powder $\bullet$ hot injection $\cdot$ chalcogenide $\cdot$ group 14 elements

\section{References}

[1] A. A. Khan, I. Khan, I. Ahmad, Z. Ali, Mat. Sci. Semicond. Process. 2016, 48, 85-94

[2] Y. Sadia, T. Ohaion-Raz, O. Ben-Yehuda, M. Korngold, Y. Gelbstein, J. Solid State Chem. 2016, 241, 79-85.

[3] a) D. M. Rowe In CRC Handbook of Thermoelectrics, CRC Press, Boca Raton, FL, 1995; b) J. R. Drabble, C. H. L. Goodman, J. Phys. Chem. Solids 1958, 5, 142-144; c) W. J. Xie, J. He, H. Jung Kang, X. F. Tang S. Zhu, M. Laver, S. Wang, J. R. D. Copley, C. M. Brown, Q. Zhang, T. M. Tritt, Nano Lett., 2010, 10, 3283-3289; A.-L. Hansen, T. Dankwart M. Winkler, J. Ditto, D. C. Johnson, J. D. Koenig, K. Bartholomé, L. Kienle, W. Bensch, Chem. Mater. 2014, 26, 6518-6522; d) Y. Zhang G. D. Stucky, Chem. Mater. 2014, 26, 837-848; T. Dankwort, A.-L. Hansen, M. Winkler, U. Schürmann, J. D. Koenig, D. C. Johnson, N. F. Hinsche, P. Zahn, I. Mertig, W. Bensch, L. Kienle, Phys. Status Solidi A 2016, 213, 662-671.

[4] G. Xiao, Y. Wang, J. Ning, Y. Wei, B. Liu, W. W. Yu, G. Zou, B. Zou, RSC Adv. 2013, 3, 8104-8130.

[5] Z.-G. Chen, G. Han, L. Yang, L. Cheng, J. Zou, Progress Nat. Sci. Mater. Internat. 2012, 22, 535-549. 
[6] a) Y. Z. Pei, X. Shi, A. LaLonde, H. Wang, L. D. Chen, G. J. Snyder, Nature 2011, 473, 66-69; b) D. Wu, L. D. Zhao, X. Tong, W. Li, L. Wu Q. Tan, Y. L. Pei, L. Huang, J.-F. Li, Y. M. Zhu, M. G. Kanatzidis, J. He, Energy Environ. Sci. 2015, 8, 2056-2068; c) H. J. Wu, L. D. Zhao, F. S Zheng, D. Wu, Y. L. Pei, X. Tong, M. G. Kanatzidis, J. Q. He, Nat Commun. 2014, 5, 4515; d) Z. Z. Jian, Z. W. Chen, W. Li, J. Yang, W Q. Zhang, Y. Z. Pei, J. Mater. Chem. C 2015, 3, 12410-12417.

[7] M. Gao, Y. Xu, J. Jiang, S. Yu, Chem. Soc. Rev. 2013, 42, 2986-3017

[8] a) C. Chen, H. Wang, Y. Chen, T. Day, G. J. Snyder, J. Mater. Chem. A 2014, 2, 11171-11176; b) Q. Zhang, E. K. Chere, J. Sun, F. Cao, K. Dahal, S. Chen, G. Chen, Z. F. Ren, Adv. Energy Mater. 2015, 5, 1500360 ; c) Y. M. Han, J. Zhao, M. Zhou, X. X. Jiang, H. J. Leng, L. F. Li, J. Mater. Chem. A 2015, 3, 4555-4559; d) F. Q. Wang, S. Zhang, J. Yu, Q. Wang, Nanoscale 2015, 7, 15962-15970.

[9] L. D. Zhao, S. Lo, Y. Zhang, H. Sun, G. J. Tan, C. Uher, C. Wolverton, V. P. Dravid, M. G. Kanatzidis, Nature 2014, 508, 373-377.

[10] P. Ramasamy, D. Kwak, D.-H. Lim, H.-S. Ra, J.-S. Lee, J. Mater. Chem. C 2016, 4, 479-485.

[11] S. Schulz, S. Heimann, K. Kaiser, O. Prymak, W. Assenmacher, J. T. Brüggemann, B. Mallik, A.-V. Mudring, Inorg. Chem. 2013, 52, 1432614333.

[12] a) G. Bendt, S. Lapsien, P. Steiniger; D. Bläser, C. Wölper, S. Schulz, Z. Anorg. Allg. Chem. 2015, 641, 797-802; b) P. Steiniger, G. Bendt, D. Bläser, C. Wölper, S. Schulz, Chem. Commun. 2014, 50, 15461-15463.

[13] J. R. Thompson, I. Y. Ahmet, A. L. Johnson, G. Kociok-Köhn, Eur. J. Inorg. Chem. 2016, 4711-4720.

[14] M. Rusek, G. Bendt, C. Wölper, S. Schulz, Eur. J. Inorg. Chem. 2016, 3673-3679.

[15] H. Schumann, J. Kaufmann, S. Dechert, H.-G. Schmalz, Tetrahedron Letters 2002, 43, 3507-3511.

[16] N. N. Zemlyansky, I. V. Borisova, V. N. Khrustalev, M. Yu. Antipin, Y. A. Ustynyuk, M. S. Nechaev, V. V. Lunin, Organometallics 2003, 22, 5441 5446

[17] a) R. R. Aysin, L. A. Leites, S. S. Bukalov, V. N. Khrustalev, I. V. Borisova, N. N. Zemlyanskii, A. Y. Smirnov, M. S. Nechaev, Russ. Chem. Bull. Int. Ed. 2011, 60, 69-80; b) N. N. Zemlyansky, I. V. Borisova, M. G. Kuznetsova, V. N. Khrustalev, Y. A. Ustynyuk, M. S. Nechaev, V. V. Lunin, J. Barrau, G. Rima, Organomet. 2003, 22, 16751681.

[18] The crystallization was performed on the diffractometer at a temperature of $170 \mathrm{~K}$ using a miniature zone melting procedure with focused infrared-laser-radiation according to: R. Boese, M. Nussbaumer, "In Situ Crystallisation Techniques", In "Organic Crystal Chemistry", Ed. D.W. Jones, Oxford University Press, Oxford, England (1994) 20-37.

[19] P. Pyykkö, M. Atsumi, Chem. Eur. J. 2009, 15, 186-197.

[20] M. Mantina, A. C. Chamberlin, R. Valero, C. J. Cramer, D. G. Truhlar, J. Phys. Chem. A 2009, 113, 5806-5812.

[21] N. N. Zemlyansky, I. V. Borisova, M. G. Kuznetsova, V. N. Khrustalev, Y. A. Ustynyuk, M. S. Nechaev, V. V. Lunin, J. Barrau, G. Rima, Organometallics 2003, 22, 1675-1681.
[22] V. N. Khrustalev, I. A. Portnyagin, N. N. Zemlyansky, I. V. Borisova, Y. A. Ustynyuk, M. Y. Antipin, J. Organomet. Chem. 2005, 690, 1056-1062.

[23] a) Z. Li, Y. Chen, J.-F. Li, H. Chen, L. Wang, S. Zheng, G. Lu, Nano Energy 2016, 28, 78-86; b) S. Guo, A. F. Fidler, K. He, D. Su, G. Chen Q. Lin, J. M. Pietryga, V. I. Klimov, J. Am. Chem. Soc. 2015, 137, 15074-15077; c) H. S. Im, Y. Myung, K. Park, C. S. Jung, Y. R. Lim, D. M. Jang, J. Park, RSC Adv. 2014, 4, 15695-15701; d) X. Liu, Y. Li, B. Zhou, X. Wang, A. N. Cartwright, M. T. Swihart, Chem. Mater. 2014 26, 3515-3521; e) S. Liu, M. R. Buck, A. J. Biacchi, E. J. Popczun, R. E. Schaak, Chem. Mater. 2013, 25, 2163-2171; f) X. Guo, M. Li, W.-H. Zhang, X. Liu, C. Li, Angew. Chem. 2011, 123, 12256-12259; Angew. Chem. Int. Ed. 2011, 50, 12050-12053; g) M. A. Franzman, C. W. Schlenker, M. E. Thompson, R. L. Brutchey, J. Am. Chem. Soc. 2010 132, 4060-4061; h) M. A. Caldwell, S. Raoux, R. Y. Wang, H.-S. P. Wong, D. J. Milliron, J. Mater. Chem. 2010, 20, 1285-1291; i) C. Erk, R. B. Wehrspohn, M. Steinhart, S. Schlecht, Phys. Stat. Sol. B 2010, 247, 2393-2400; j) M. V. Kovalenko, W. Heiss, E. V. Shevchenko, J.-S. Lee, H. Schwinghammer, A. P. Alivisatos, D. V. Talapin, J. Am. Chem. Soc 2007, 129, 11354-11355; k) S. Schlecht, M. Budde, L. Kienle, Inorg Chem. 2002, 41, 6001-6005.

[24] a) P. Reiss, M. Carrière, C. Lincheneau, L. Vaure, S. Tamang, Chem Rev. 2016, 116, 10731-10819; b) D. J. Lewis, P. Kevin, O. Bakr, C. A. Muryn, M. A. Malik, P. O'Brien, Inorg. Chem. Frontiers 2014, 1, 577 598; c) S. R. Alvarado, Y. Guo, T. Purnima, A. Ruberu, E. Tavasoli, J. Vela, Coord. Chem. Rev. 2014, 263-264, 182-196.

[25] a) R. L. Brutchey, Acc. Chem. Res. 2015, 48, 2918-2926; b) Y. Guo S.R. Alvarado, J. D. Barclay, J. Vela, ACS Nano 2013, 7, 3616-3626.

[26] a) N. O. Boadi, M. A. Malik, P. O’Brien, J. A. M. Awudza, Dalton Trans. 2012, 41, 10497-10506; b) G. Gupta, T.-M. Jeong, C. G. Kim, J. Kim Materials Letters 2015, 156, 121-124.; P. Ramasamy, D. Kwak, D.-H. Lim, H.-S. Ra, J.-S. Lee, J. Mater. Chem. C 2016, 4, 479-485; c) R. E. Abutbul, E. Segev, S. Samuha, L. Zeiri, V. Ezersky, G. Makov, Y. Golem, CrystEng Comm 2016, 18, 1918-1923; d) K. Tyagi, B. Gahtori, S. Bathula, N. K. Singh, S. Bishnoi,S. Auluck, A. K. Srivastava, A. Dhar, RSC Adv. 2016, 6, 11562-11569; e) D. J. Lewis, P. Kevin, O. Bakr, C A. Muryn, M. A. Malik, P. O’Brien, Inorg. Chem. Front. 2014, 1, $577-$ 598.

[27] H. Schumann, J. Kaufmann, S. Dechert, H.-G. Schmalz, Tetrahedron Letters 2002, 43, 3507-3511.

[28] M. R. Detty, M. D. Seidler, J. Org. Chem. 1982, 47, 1354-1356.

[29] G. M. Sheldrick, Acta Crystallogr. 1990, A46, 467-473.

[30] a) G. M. Sheldrick, SHELXL-2014, Program for the Refinement of Crystal Structures University of Göttingen, Göttingen (Germany) 2014. (see also: Sheldrick, G. M. Acta Crystallogr. 2008, A64, 112-122.); shelXle, A Qt GUI for SHELXL, C. B. Hübschle, G. M. Sheldrick, J. Appl. Cryst. 2011, 44, $1281-1284$.

[31] P. Scherrer, Nachr. Ges. Wiss. Gött., Math.-Phys. KI. 1918, 2, 98-100. 


\section{Entry for the Table of Contents}

\section{FULL PAPER}

Group 14 chalcogenides ME $(M=G e$, $\mathrm{Sn}, \mathrm{Pb} ; \mathrm{E}=\mathrm{S}$, Se, Te) were synthesized by reactions of intramolecular-stabilized, homoleptic germanium, tin and lead alkoxides $\mathrm{M}\left(\mathrm{OCH}_{2} \mathrm{CH}_{2} \mathrm{NR}_{2}\right)_{2}$ with $\left(\mathrm{Me}_{3} \mathrm{Si}\right)_{2} \mathrm{~S}$ and $\left(\mathrm{Et}_{3} \mathrm{Si}\right)_{2} \mathrm{E}(\mathrm{E}=\mathrm{Se}, \mathrm{Te})$ via hot injection method. The solid state structure of $\mathrm{Ge}\left(\mathrm{OCH}_{2} \mathrm{CH}_{2} \mathrm{NEt}_{2}\right)_{2} 1$ was determined by single crystal $\mathrm{X}$-ray diffraction and the materials were characterized by XRD, SEM and EDX.
Monika Rusek, Georg Bendt, Christoph Wölper, Dieter Bläser and Stephan Schulz*

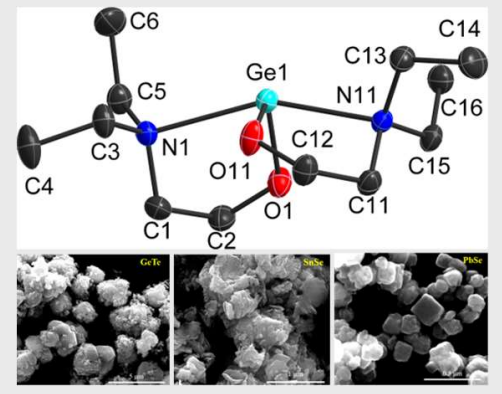

Page No. - Page No.

Intramolecular-stabilized Group 14 Alkoxides - Promising Precursors for the Synthesis of Group 14-

Chalcogenides by Hot-Injection Method 


\section{DuEPublico}

This text is made available via DuEPublico, the institutional repository of the University of Duisburg-Essen. This version may eventually differ from another version distributed by a commercial publisher.

DOI: $\quad 10.1002 /$ zaac. 201700029

URN: urn:nbn:de:hbz:464-20201210-164730-8

This is the peer reviewed version of the following article: Z. Anorg. Allg . Chem. 2017, 643, 676-682, which has been published in final form at:

https://doi.org/10.1002/zaac.201700029

All rights reserved. 